\title{
Traumatic brain injury and vestibulo-ocular function: current challenges and future prospects
}

\section{Bridgett Wallace ${ }^{1-4}$ Jonathan Lifshitz ${ }^{4-8}$}

'360 Balance and Hearing, Department of Physical Therapy, Austin, TX, ${ }^{2}$ Concussion Health, Department of Clinical Education, Austin, TX, ${ }^{3}$ Conquering Concussions, Scottsdale, AZ, ${ }^{4}$ Barrow Neurological Institute at Phoenix Children's Hospital, Phoenix, AZ, ${ }^{5}$ Department of Child Health, University of Arizona College of Medicine-Phoenix, Phoenix, AZ, ${ }^{6}$ The CACTIS Foundation, Scottsdale, ${ }^{7}$ Phoenix VA Healthcare System, Phoenix, AZ, ${ }^{8}$ Department of Psychology, Arizona State University, Tempe, AZ, USA
Correspondence: Bridgett Wallace Concussion Health, 5608 Parkcrest Drive, Suite 100, Austin, TX 7873I, USA $\mathrm{Tel}+8883134443$

Email bridgett@concussionhealth.com
This article was published in the following Dove Press journal:

Eye and Brain

6 September 2016

Number of times this article has been viewed
Abstract: Normal function of the vestibulo-ocular reflex (VOR) coordinates eye movement with head movement, in order to provide clear vision during motion and maintain balance. VOR is generated within the semicircular canals of the inner ear to elicit compensatory eye movements, which maintain stability of images on the fovea during brief, rapid head motion, otherwise known as gaze stability. Normal VOR function is necessary in carrying out activities of daily living (eg, walking and riding in a car) and is of particular importance in higher demand activities (eg, sports-related activities). Disruption or damage in the VOR can result in symptoms such as movement-related dizziness, blurry vision, difficulty maintaining balance with head movements, and even nausea. Dizziness is one of the most common symptoms following traumatic brain injury (TBI) and is considered a risk factor for a prolonged recovery. Assessment of the vestibular system is of particular importance following TBI, in conjunction with oculomotor control, due to the intrinsic neural circuitry that exists between the ocular and vestibular systems. The purpose of this article is to review the physiology of the VOR and the visual-vestibular symptoms associated with TBI and to discuss assessment and treatment guidelines for TBI. Current challenges and future prospects will also be addressed.

Keywords: traumatic brain injury, concussion, vestibular, ocular motor, symptoms

\section{Introduction}

Vestibular symptoms can occur immediately following traumatic brain injury (TBI) and can be some of the most problematic sequelae, which contribute to a prolonged recovery. ${ }^{1-3}$ Assessment of the vestibular system post TBI generally focuses on sensory organization or balance testing, ${ }^{4-7}$ while testing the vestibulo-ocular reflex (VOR) continues to be largely overlooked. The literature is particularly sparse in incorporating VOR exercises into a rehabilitation program post injury, or articulating the importance of peripheral versus central vestibular involvement. ${ }^{8} \mathrm{VOR}$ originates from the semicircular canals (SCCs) of the inner ear to elicit compensatory eye movements that stabilize images on the fovea during brief and rapid head motion. The compensatory eye movements involved in gaze stability ensure clear vision during angular head motion and non-angular head movement, which are necessary for activities of daily living (ADL) as well as higher demand activities associated with sports. VOR is vulnerable to disruption and even damage by mild TBI, resulting in symptoms such as movement-related dizziness, blurry vision, unsteadiness, and even nausea. ${ }^{1,7,9,10}$ Dizziness is reported in 50\% of concussed athletes (the second most common symptom following a headache), ${ }^{3}$ suggesting visual and/or vestibular impairments. ${ }^{9-13}$ Further, 
dizziness at the time of injury is the single greatest risk factor for a prolonged recovery. ${ }^{14}$ The purpose of this article is to review the physiology of the VOR in order to address the pathology and symptoms as a consequence of TBI, as well as the challenges and future prospects for vestibulo-ocular involvement in TBI management.

\section{Peripheral vestibular system anatomy}

The peripheral vestibular system is composed of the bony labyrinth, the membranous labyrinth, and the specialized sensory hair cells within the inner ear (Figure 1). The inner ear has two distinct divisions: 1) the cochlea for hearing and 2) the vestibular system for balance (Figure 2). The bony labyrinth is located within the temporal bone on each side of the head and is filled with the perilymph. The membranous labyrinth is suspended within the bony labyrinth and is filled with endolymph. The inner ear fluids are maintained at constant volumes and contain specific concentrations of sodium, potassium, chloride, and other electrolytes. The perilymph has a higher concentration of sodium than potassium, whereas the endolymph has a higher concentration of potassium than sodium. ${ }^{15}$ Mechanical conduction of sound waves and head motion cause the specialized sensory hair cells to move within the endolymph to detect sound wave pressure in the cochlea and head acceleration in the labyrinth (Figure 3). The labyrinth consists of two distinct sensory mechanisms: SCCs, which detect angular head accelerations, and the otolith organs that detect linear head accelerations (Figure 4). The three SCCs (anterior, posterior, and horizontal) provide the sensory neural input related to angular head acceleration, which is processed to coordinate compensatory eye and head movements via the VOR.

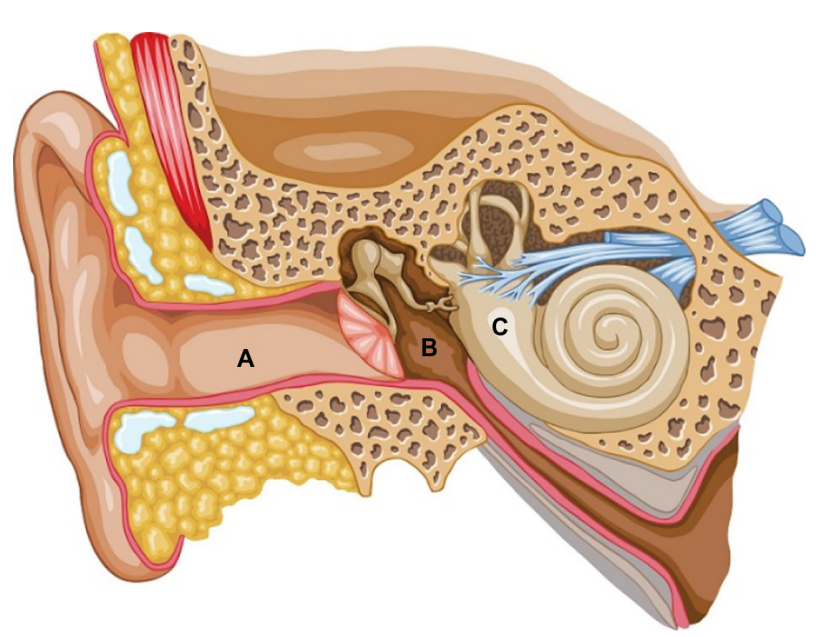

Figure I Representation of the ear from the outer ear $(\mathbf{A})$ to the middle ear $(\mathbf{B})$ to the inner ear $(\mathbf{C})$.

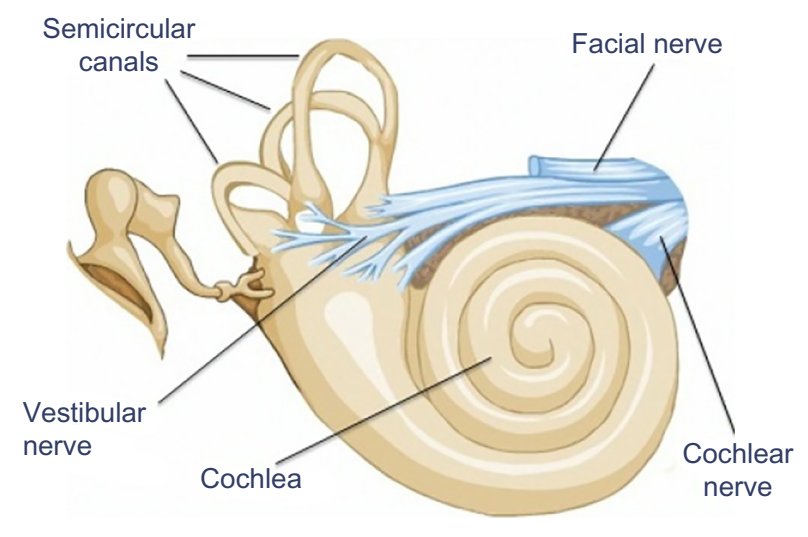

Figure 2 Representation of the two divisions of the inner ear.

Note: The cochlea is the snail-shaped portion on the right, and the semicircular canals on the left represent the vestibular system.

The otolith organs (utricle and saccule) provide sensory neural input related to linear head acceleration. The utricle senses linear movements of the head in the horizontal plane, while the saccule senses linear movements of the head in the vertical plane. Additionally, the utricle and saccule convey information about spinal and leg musculature for balance strategies (ankle, hip, and stepping) via the vestibular spinal reflex (VSR), which is primarily to maintain upright posture during movement. The otoliths further convey information regarding the direction of gravity through head tilt, which is incorporated into locomotion. The function of the otolith organs is accomplished by otoconia - calcium carbonate crystals that are denser than the surrounding endolymph remaining partially stable while the head moves around them (Figure 5). It is important to note that the utricle and saccule also have connections with eyes muscles as noted with the SCC. However, the direct pathways of rotational

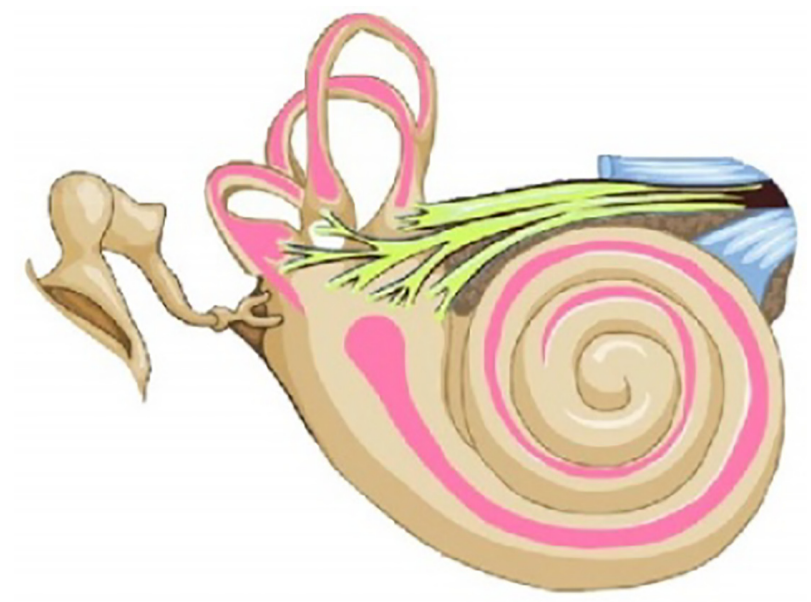

Figure 3 Representation of the endolymph (pink), which is the fluid contained in the membranous labyrinth of the inner ear and has a higher level of potassium than sodium. 


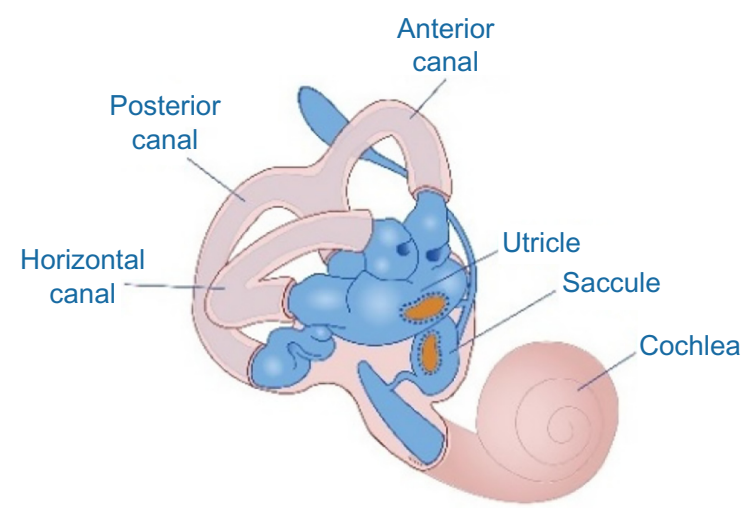

Figure 4 Representation of the three semicircular canals that detect angular head accelerations and the two otolith organs (utricle and saccule) that detect linear head accelerations.

Note: Adapted with permission from Benign Paroxysmal Positional Vertigo [webpage]. Copyright (c) 2016, Timothy C. Hain, MD. [Updated Dec 27 2006]. Available from http://www.dizziness-and-balance.com/images/master-ear.jpg.

compensatory eye movements are much greater than those of linear translation, resulting in minimal contributions from the otoliths to the VOR as compared to the SCC.

If otoconia become displaced from the utricle into the SCCs, then brief spells of vertigo are experienced related to position changes, a condition called benign paroxysmal positional vertigo (Figure 6). TBI is a common cause of benign paroxysmal positional vertigo in the adult population, although it rarely occurs in adolescents. ${ }^{10,16,17}$ The

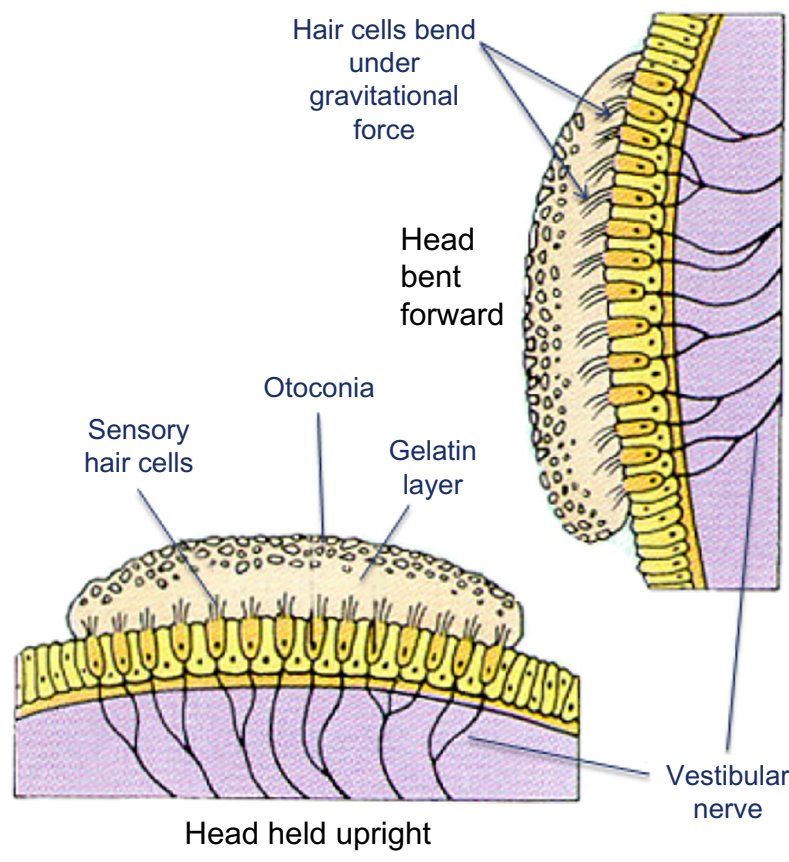

Figure 5 The bottom image represents orientation of hair cells within the utricle when the head is upright.

Notes: The hair cells are surrounded by a gelatinous substance and hold the microscopic otoconia. The image on the right represents the response with pitching the head forward, which results in a deflection of the hair cells due to a gravitational pull.

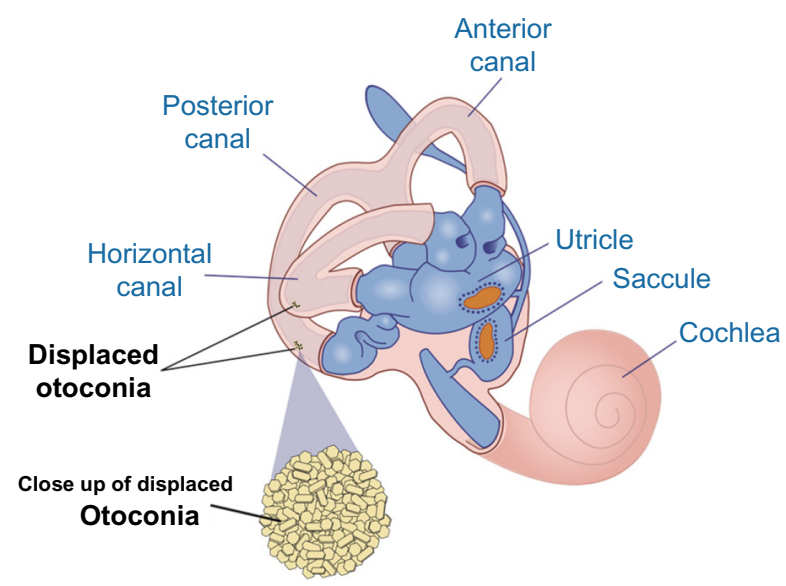

Figure 6 Representation of dislodged otoconia in both the posterior and horizontal canal.

Note: Adapted with permission from Benign Paroxysmal Positional Vertigo [webpage]. Copyright (C) 2016, Timothy C. Hain, MD. [Updated Dec 27 2006]. Available from http://www.dizziness-and-balance.com/images/master-ear.jpg. .

first-order information processing from the inner ear involves a number of associated reflexes: the vestibulocollic reflex (VCR), the cervico-ocular reflex (COR), the cervicospinal reflex (CSR), and the cervicocollic reflex (CCR). VCR acts on the neck muscles to stabilize the head in space during body movements and is considered a righting reflex. VCR lessens head oscillations that occur in more rapid, dynamic movements. ${ }^{18}$ Although the neural pathways and actions are not fully understood, it is suspected that VCR is mediated through the otolith organs and medial VSR ${ }^{19} \mathrm{COR}$ acts on eye movements similar to VOR, receiving input from the neck proprioceptors, and is of particular importance as a compensatory strategy if bilateral vestibular nerve loss occurs. COR is not thought to make any notable contributions to gaze stability in normal subjects because the gain is notably less than VOR. ${ }^{20} \mathrm{CSR}$ acts on the extremities and is synonymous with the tonic neck reflex. CSR interacts with VSR. ${ }^{21}$ Finally, CCR acts on deep neck muscles to assist in head stabilization during head and body movements. Body rotation with the head stabilized elicits CCR, whereas head rotation with the body stabilized elicits VOR. ${ }^{22}$ For purposes of this review, we focus primarily on VOR.

\section{Mechanism of VOR}

SCCs are approximately orthogonal $\left(90^{\circ}\right)$ to one another and provide information about the angular movements of the head in three independent planes. The anterior canal on one side is coplanar with the posterior canal on the opposite side, while the horizontal canals of each side are coplanar to one another. Thus, the six SCCs are grouped into three coplanar pairs: the right anterior and the left posterior; the 


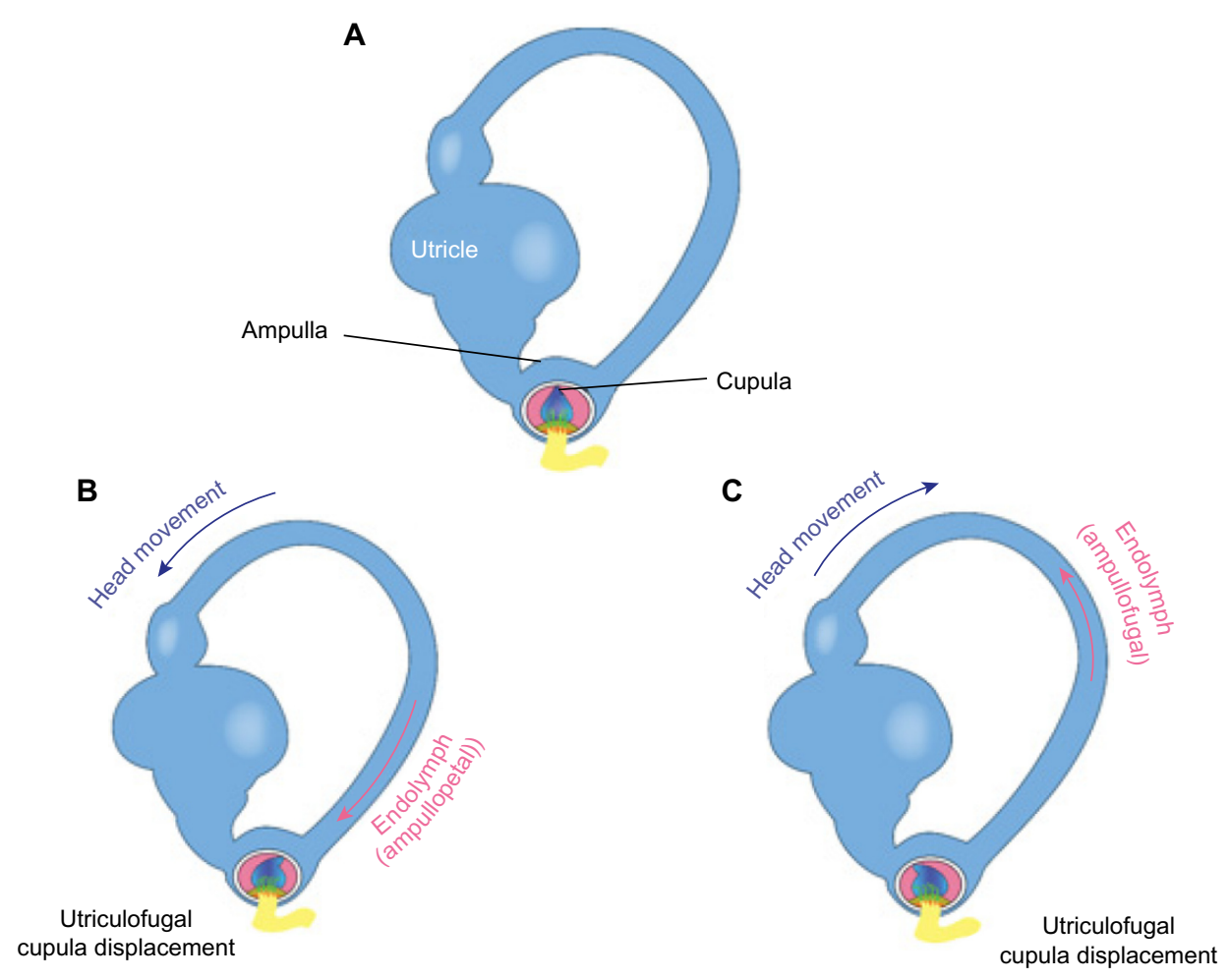

Figure 7 Representation of the endolymphatic flow.

Notes: (A) Orientation of the cupula when the head is upright and stationary. (B) Head movement in one direction, resulting in endolymphatic flow in the opposite direction and toward the cupula (ampullopetal). Ampullopetal flow causes deflection of the cupula toward the utricle (utriculopetal). (C) Head movement that results in endolymph moving away from the amupulla (ampullofugal), causing deflection of the cupula away from the utricle (utriculofugal).

left anterior and the right posterior; and the right and left horizontal canals. The horizontal canals tilt upward by an estimated $20^{\circ}-30^{\circ}$ from the horizontal plane when the head is upright, although three-dimensional multiplanar computerized tomography calculated the horizontal canal to be more commonly tilted by $18^{\circ} .{ }^{23}$ SCCs' responses are considered maximal when the head moves in the plane of the respective canal, which is the premise for testing the horizontal VOR function with $\sim 20^{\circ}$ of flexion. ${ }^{23,24}$

Each SCC has an ampulla, an expanded bubble-like structure that contains the hair cells (crista ampullaris), as well as a fan-like structure known as the cupula, which separates the canal from the vestibule. The cupula has the same density as the endolymph and therefore SCC does not respond to changes in the orientation of the head with respect to gravity. With angular head movements, however, the inertia of the endolymph results in a pressure on the cupula, which stimulates the hair cells through facilitation (increased firing rate) or inhibition (decreased firing rate). If the fluid is moving toward the ampulla, the horizontal canal is facilitated, while the canals in the vertical plane on the same side are inhibited. Hence, neural activities of the SCC pairs are opposite, which results in a push-pull mechanism of facilitation on one side and inhibition on the other. ${ }^{15}$ The resting firing rate in the absence of motion would therefore be equal for the right and left labyrinths.

VOR neural pathways have been well documented; for purposes of this discussion, pathways will be addressed as a three-arc process: 1) detection of head rotation occurs as a result of endolymph displacement and the subsequent deflection of the cupula (as shown in Figure 7), 2) extraocular muscles on opposite sides of the head undergo inhibition and excitation, and 3 generation of eye movements takes place with the primary purpose of compensating for head movement. ${ }^{15}$ These compensatory eye movements stabilize images on the fovea and allow for clear vision during head movements.

To better understand the VOR function, we will briefly review the role of the extraocular muscles. There are six extraocular muscles that contribute to eye movements: lateral and medial rectus muscles for horizontal eye movements, superior and inferior rectus muscles primarily for vertical movements but also contributing to torsional eye movements, and superior and inferior oblique muscles primarily for torsional movements but also contributing to vertical eye movements. The extraocular muscles reside in planes that are approximately parallel to the plane of respective SCCs. The SCCs are responsible for facilitating muscles on the same 
Table I Represents the excitatory and inhibitory connections of each SCC with the muscles of both eyes, which results in specific compensatory responses between the vestibular system and eye muscles

\begin{tabular}{lll}
\hline $\begin{array}{l}\text { Semicircular } \\
\text { canal (SCC) }\end{array}$ & Excitation & Inhibition \\
\hline Posterior & $\begin{array}{l}\text { Ipsilateral superior oblique } \\
\text { Contralateral inferior }\end{array}$ & $\begin{array}{l}\text { Ipsilateral inferior oblique } \\
\text { Contralateral superior } \\
\end{array}$ \\
rectus & rectus \\
Anterior & Ipsilateral superior rectus & Ipsilateral inferior rectus \\
& Contralateral inferior & Contralateral superior \\
& oblique & oblique \\
Horizontal & Ipsilateral medial rectus & Contralateral medial rectus \\
& Contralateral lateral rectus & Ipsilateral lateral rectus \\
\hline
\end{tabular}

side and inhibiting muscles on the opposite side, as noted in Table 1. These anatomical relationships are also highlighted in Table 2 and are known as Ewald's Law $1 .{ }^{25}$ VOR maintains gaze stability through compensatory eye movements equal to head movements, which is referred to as VOR gain. For example, if the head turns $30 \% \mathrm{sec}$ to the right, then the eyes turn $30 \%$ sec to the left to maintain stability of the image on the fovea. In a healthy person, the gain is a 1:1 ratio.

\section{Central connections}

Vestibular information is primarily processed in the brainstem via afferent fibers of the eighth crania nerve (CN VIII). The signals enter the brainstem at the medulla and pons, which is known as the vestibular nuclear complex. Vestibular nuclear complex is comprised of four major nuclei (versus up to seven minor nuclei) in the floor of the fourth ventricle: superior, inferior, medial, and lateral. ${ }^{15,26}$ Most of the SCC inputs synapse with the superior and medial vestibular nuclei via first-order sensory neurons of CN VIII, while second-order

Table 2 Ewald's three laws, which govern vestibular diagnostic testing

I Stimulation of a semicircular canal (SCC) generates eye movements in the plane of that canal.

2 In the horizontal canals, movement of the endolymph toward the ampulla (ampullopetal) causes deflection of the cupula toward the utricle (utriculopetal) and results in a greater neural activity (excitation) compared to movement away from the utricle (utriculofugal).

3 In the vertical canals (anterior and posterior), movement of the endolymph away from the ampulla (ampullofugal) causes greater deflection of the cupula away from the utricle (utriculofugal) and results in a greater excitation compared to utriculopetal movement, which is opposite to that in the horizontal canals.

Note: Ewald's Law I is specific to compensatory eye movements to head movements as well as the foundation for identifying canal involvement in benign paroxysmal positional vertigo. sensory neurons send signals ipsilaterally and contralaterally via the medial longitudinal fasciculus to the oculomotor cranial nerves III, IV, and VI. A third motor neuron excites the extraocular muscles, causing conjugate eye movements that are equal to and opposite of head movements. ${ }^{27}$ This results in gaze stabilization during head movements and represents the three-arc model previously discussed. ${ }^{15,27}$

The vestibular system is unique in that it also sends collaterals to the cerebellum via the inferior cerebellar peduncle, with a role in modulating or fine-tuning the VOR. More specifically, the flocculonodular lobe and fastigial nuclei regulate vestibular and oculomotor function. The cerebellum is also considered the adaptive processor of vestibular information, specifically as related to error messages, and assists in coordination, maintaining posture, and modulation of vestibular reflexes. ${ }^{28}$

There are additional vestibular connections to the thalamus, cerebral (vestibular) cortex, and reticular formation. These extensive connections result in a coordinated effort between the vestibular system and other central networks to contribute to arousal and conscious awareness of the head and body in space. ${ }^{27}$

\section{The vestibular blood supply}

The anterior inferior cerebellar artery branches into the labyrinthine artery, which is the main blood supply route for the peripheral vestibular system. Anterior inferior cerebellar artery bifurcates with the superior vestibular artery supplying the utricle, superior and horizontal SCC, and a small portion to the saccule. The other branch (common cochlear artery) further bifurcates to supply the cochlea, majority of the posterior SCC, and remainder of the saccule. The venous flow is similar to the arterial flow, of which the superior vein drains the superior and horizontal SCC and utricle, while the inferior vein drains the saccule, posterior SCC, and the majority of the saccule. ${ }^{15}$

\section{Visual-vestibular functional integration}

As previously discussed, the primary purpose of the VOR is gaze stability - maintaining fixation of images on the fovea during head motion. The fovea is responsible for the sharpest central vision and is of particular importance in reading, driving, and feature detection. The oculomotor system (pursuit, saccades and optokinetic) fulfill this role when the object of interest changes. For example, compensation occurs through smooth pursuit (tracking) at slower speeds, but faster speeds require more reflexive responses via saccades that are not capable by the pursuit system.

The slow phase of optokinetic nystagmus (OKN) is the same as smooth pursuit, and the fast phase is the same as 
saccades. The OKN system, however, is considered a reflexive mechanism that is the equivalent of the reflexive vestibular system. When tracking an object during sustained head movements, the VOR must be suppressed. This visual-vestibular interaction is essential for individuals to successfully move around in their environment and without provocation of symptoms. The optokinetic system allows for gaze stabilization in sustained head movements, or when the head is still but objects are moving in a timely fashion (eg, counting train cars that are passing by while the head is still). The optokinetic system is also activated with full field or a large visual scene - objects that fill at least $80 \%$ of the visual field. ${ }^{15}$ These features of the OKN and the VOR previously discussed can be used for the diagnosis of TBI symptoms and incorporated into approaches for treating persistent symptomatology.

When the head and eyes are moving together to track a single object, VOR must be suppressed in order to maintain focus on the target. ${ }^{29}$ Dysfunction in suppression of VOR is a contributing factor to motion sensitivity, a symptom associated with slower recovery from postconcussion syndrome (PCS) symptoms. ${ }^{2,3,30}$ As previously stated, additional symptoms associated with impairments in the visual-vestibular systems can include dizziness, unsteadiness, headaches, blurriness, decreased concentration, difficulty reading, and even nausea. ${ }^{1,7,9,10}$

\section{TBI and VOR}

VOR remains sensitive and vulnerable to TBI of all severities. ${ }^{1,30-32}$ Dizziness is one of the most common symptoms following head trauma ${ }^{3}$ and serves as a primary predictor of a prolonged recovery. ${ }^{1-3}$ Identifying the etiology of the dizziness, nausea, and/or balance problems following TBI is particularly challenging, as similar symptoms can be the result of brain, inner ear, visual, and/or spinal injury.

Vestibular disorders associated with TBI can be central or peripheral, although peripheral disorders are much more common. ${ }^{33}$ The more serious life-threatening central causes of central dizziness are typically identified by imaging, whereas imaging has low sensitivity for peripheral vestibular dysfunction. ${ }^{34}$ For these injuries, the clinical examination must include a comprehensive history regarding symptoms, identifying risk factors for PCS, which include dizziness, history of migraines, previous concussions, collision-sport participation, female sex, persistent headaches, amnesia, younger age, history of mood disorder, and/or presence of a learning disorder. ${ }^{2,35-37}$

Further, it is critical to identify activities that exacerbate and/or decrease the symptoms. Since dizziness is a primary symptom of PCS, but represents an umbrella term with different meanings to each individual, it is recommended to ask the individual to describe their dizziness without using the word itself. The goal is to distinguish dizziness symptoms into the following four categories: ${ }^{38}$

1. Vertigo: It is an illusion of movement, which always includes a spinning or rotational sensation. The individual feels as if 1) the room is spinning, and/or 2) it is a feeling inside their head. The individual may also describe their vertigo as a sudden falling sensation or that the ground moving, which can be provoked or exacerbated by anxiety.

2. Presyncope: The feeling of nearly passing out, fainting and/or blacking out.

3. Lightheadedness: It is often associated with a faint-like feeling or as if the individual may pass out. Lightheadedness is typically associated with a non-vestibular disorder such as hypoglycemia, orthostatic hypotension, and/or anxiety.

4. Unsteadiness: It is commonly described as feeling "off," and the individual may be afraid he or she will fall. Some individuals may associate their unsteadiness with their feet, which is suggestive of loss of sensation and/or lower extremity weakness. Some also describe a drunk-like, intoxicated feeling common in both peripheral and central vestibular disorders.

Table 3 identifies common characteristics of symptoms associated with peripheral vestibular dysfunction after TBI. ${ }^{15}$ In TBI and concussion management, an accurate diagnosis is critical to developing the most appropriate plan of care. An effective diagnosis can identify those individuals for whom starting a rehabilitation program is not suitable and may require additional referral(s). A comprehensive initial examination, understanding of the patient's symptoms, and clinical examination by an experienced clinician can provide an accurate diagnosis, which is the cornerstone for a successful recovery. ${ }^{39,40}$

\section{Clinical assessment of the oculomotor system}

Disruption in oculomotor control, or eye movement, has long been associated with TBI, ${ }^{41}$ even dating back to ancient times. ${ }^{42}$ Prior to assessing the VOR, examination of the oculomotor system provides valuable information to distinguish central from peripheral vestibular pathology. At a minimum, assessment of the oculomotor system should include the following.

\section{Alignment}

Evaluation of eye position is the first step in the examination of oculomotor control, because misalignment can affect all eye movement systems. More obvious misalignments can be 
identified through simple observation and, if noted, warrants referral to an optometrist or ophthalmologist, especially if strabismus is a new onset post injury. More subtle horizontal or vertical misalignments can be detected using the cover test, which is considered reliable even among more inexperienced examiners. ${ }^{43}$ Misalignment of the eyes can cause blurriness, dizziness, headaches, and/or diplopia.

\section{Range of motion}

The range of oculomotor control can be performed during smooth pursuit testing, but requires observations through the nine cardinal positions of gaze versus observation during H-pattern only. In the absence of damage, individuals can move his or her eyes with conjugate gaze into all extremes of the visual field.

\section{Smooth pursuit}

Normal smooth pursuit is a smooth movement of the eyes tracking a slow moving target from one point of fixation to another in a timely manner. Evaluation of the tracking system assesses how timely and smoothly the eyes follow a target across the field of vision while the head is in the neutral position. Smooth pursuit is often tested in the H-pattern across the visual field to examine cranial nerves III, IV, and VI. Damage to smooth pursuit systems can be detected as imprecise following of the target, observed by corrective, or catch-up, saccades similar to nystagmus. Normal tracking declines with age and is sensitive to medications, inattention, and anxiety. ${ }^{44}$ Notable eye movement asymmetry during tracking suggests a cranial nerve palsy, which may be associated with TBI or the central nervous system dysfunction. Following TBI, it is also important to assess the interaction between the smooth pursuit system and the VOR via the VOR cancellation test.

\section{Saccades}

The saccadic system produces a rapid eye movement from one point of fixation to another point of fixation. Normal saccades bring the image of the new target onto the fovea for clear viewing. Abnormal saccades can include decreased velocity to the target, increased latency to initiate the movement, and/or corrections (either under or overshooting) the target. ${ }^{45}$ Abnormal saccades suggest disruption in normal brainstem and/or cerebellum function ${ }^{44}$ and have been measured in symptomatic individuals following whiplash injury. ${ }^{46}$

\section{Vergence}

The vergence system aligns both foveas onto a common target at varying distances through disjunctive eye movements; each eye moves in a direction opposite to the other. Normal vergence results in symmetrical and coordinated eye movement inward (convergence) or outward (divergence),

Table 3. Summary of vestibular disorders associated with head trauma and corresponding clinical presentation (adapted from Ernst). ${ }^{10}$

\begin{tabular}{|c|c|c|c|c|}
\hline Vestibular disorder & Duration of vertigo & Exacerbating factors & Diagnostic tests & Treatment \\
\hline BPPV & $<I$ minute & Position changes & $\begin{array}{l}\text { Dix-Hallpike (super/posterior } \\
\text { scc) or Roll Test (horizontal } \\
\text { scc) - clinical and/or with } \\
\text { video goggles/frenzel lenses }\end{array}$ & $\begin{array}{l}\text { Canal specific repositioning } \\
\text { maneuvers }\end{array}$ \\
\hline Central Vertigo & Varies & Non-specific/more constant & Neuro exam; Imaging & $\begin{array}{l}\text { Pharmaceutical management; } \\
\text { Habituation; Physical therapy }\end{array}$ \\
\hline $\begin{array}{l}\text { Delayed Endolymphatic } \\
\text { Hydrops/Meniere's } \\
\text { Disease }\end{array}$ & Minutes to Hours & $\begin{array}{l}\text { Intermittent spells - possibly } \\
\text { related to diet, allergies, other } \\
\text { illnesses, stress, hormonal } \\
\text { changes, migraines and/or } \\
\text { barometric pressure changes }\end{array}$ & $\begin{array}{l}\text { Comprhensive audiogram; } \\
\text { Electrocochleography } \\
\text { (ECoG) and Vestibular } \\
\text { Evoked Myogenic } \\
\text { Potentials (VEMP) }\end{array}$ & $\begin{array}{l}\text { Lifestyle changes and/or } \\
\text { pharmaceutical management } \\
\text { most conservative; Intratympanic } \\
\text { Gentamicin (ITG); Vestibular } \\
\text { nerve section (most invasive) }\end{array}$ \\
\hline $\begin{array}{l}\text { Labyrinthine } \\
\text { Concussion }\end{array}$ & Hours to Days & $\begin{array}{l}\text { Movement-related dizziness } \\
\text { and/or unsteadiness; Possibly } \\
\text { position changes }\end{array}$ & $\begin{array}{l}\text { Comprehensive audiogram; } \\
\text { Videonystagmography } \\
\text { (VNG); Computerized } \\
\text { Vestibular Ocular Reflex } \\
\text { (VOR) testing }\end{array}$ & $\begin{array}{l}\text { Acute: pharmaceutical } \\
\text { management (eg, anti-emetic, } \\
\text { steroids); Chronic: vestibular } \\
\text { therapy }\end{array}$ \\
\hline $\begin{array}{l}\text { Perilymphatic Fistula/ } \\
\text { Superior Canal } \\
\text { Dehiscence (SCD) }\end{array}$ & $\begin{array}{l}\text { Minutes to Hours; } \\
\text { may not be present }\end{array}$ & $\begin{array}{l}\text { Similar to hydrops; pressure } \\
\text { changes; loud sounds }\end{array}$ & $\begin{array}{l}\text { Comprehensive audiogram } \\
\text { with VEMP and High } \\
\text { Resolution CT scan } \\
\text { (temporal) }\end{array}$ & $\begin{array}{l}\text { Conservative per patient } \\
\text { education to avoid straining and } \\
\text { loud noises; Pharmaceutical as } \\
\text { noted with hydrops; Surgical } \\
\text { repair ("patching") }\end{array}$ \\
\hline
\end{tabular}

Note: Adapted from Ernst A, Basta D, Seidl RO, Todt I, Scherer H, Clarke A. Otolaryngol Head Neck Surg. 2(4):554-558. Copyright (C 2005 by Sage Publications, Inc. Reprinted by Permission of SAGE Publications, Inc. ${ }^{10}$

Abbreviations: BPPV, benign paroxysmal positional vertigo; SCC, semicircular canal; CT, computed tomography. 
depending on the distance of the target. Disruption of the vergence system has long been associated with TBI, ${ }^{47}$ where the majority of studies focus on combat-related injuries and more recently sports-related concussions. ${ }^{30}$

\section{VOR cancellation}

The VOR cancellation test is essentially a higher demand test of the smooth pursuit system. The subject is asked to fixate on a moving target while the head is moved in the same direction. For example, the subject can extend out their arms, clasp their hands together, and extend their thumbs. The head and body rotate together back and forth while the subjects maintain their gaze on their thumbs. Findings should be consistent with results in the smooth pursuit test. An abnormal finding is observation of corrective saccades ${ }^{44}$ and/or provocation of symptoms. ${ }^{30}$

\section{Assessment of the vestibulo-ocular system}

As previously discussed, VOR functions primarily to achieve clear vision during head movement. With a dysfunction in VOR, the gain error is too great and can result in symptoms of dizziness, unsteadiness, and even nausea. In more severe VOR dysfunction, the individual may experience oscillopsia, the sensation that objects are jumping or even the room moving during head movements. Oscillopsia and vertigo are less common with mild TBI, although movement-related dizziness is very common. Bedside tests for the VOR include the following.

- Head thrust: The head thrust test is a single, rapid head turn based on the oculocephalic reflex, or "Doll's Eye" reflex, which is performed as a standard for individuals who are in a coma or unresponsive. The head of the patient is rapidly turned in the horizontal plane to one side $\left(\sim 30^{\circ}\right)$, while the clinician observes for compensatory conjugate eye movements in the opposite direction. Halmagyi and Curthoys ${ }^{48}$ expanded the clinical application of this test to conscious patients with complete unilateral vestibular loss. The test is considered positive (abnormal) if the examiner observes corrective saccades back to the target (typically the examiner's nose). Although the head thrust test may provoke symptoms (eg, dizziness) in individuals following mild TBI, corrective saccades due to retinal slippage are rarely observed unless the injury involved significant unilateral vestibular weakness.

- Head shake test: The head shake test is used to identify the possibility of asymmetrical vestibular input due to peripheral or central pathology. ${ }^{29}$ The examiner passively performs head oscillations, or the subject does so actively. Head oscillations should occur with head flexion of $\sim 20^{\circ}$ to align the horizontal canals parallel to the ground and cover a $60^{\circ}$ arc $\left(30^{\circ}\right.$ side to side $)$ at $\sim 2 \mathrm{~Hz}(2$ cycles $/ \mathrm{s})$ for 20 repetitions. The higher velocity of the head movement exceeds pursuit system, which can only maintain gaze stabilization up to $1 \mathrm{~Hz}$. Normally, no nystagmus is expected. Some individuals with peripheral or central vestibular dysfunction show a transient nystagmus ( $\sim 30$ seconds) with the fast phase toward the unaffected ear after the head movement is stopped. ${ }^{38,49}$ A slower nystagmus that switches directions may follow. This test has improved sensitivity with Frenzel goggles or infrared video goggles, but it has low sensitivity overall as a screening tool for vestibular dysfunction. ${ }^{50}$ Abnormal results are detected in individuals with significant vestibular loss, which is typically not associated with mild TBI.

- Dynamic visual acuity (DVA) test: The DVA test was originally discussed in 1984 for assessing vestibular loss and has since become a standard clinical test for vestibular therapists. ${ }^{51}$ The test is performed in the sitting position, and the individual wears corrective lenses as needed. The individual reads the lowest line on a visual acuity chart (eg, Snellen chart), recording the smallest line read with less than three errors (eg, 20/20). The examiner flexes the patient's head by $20^{\circ}$ and continues to hold the patient's head with both hands and rotates it back and forth in the horizontal plane in a $40^{\circ}-60^{\circ}$ arc $\left(20^{\circ}-30^{\circ}\right.$ side to side to side) at $\sim 2 \mathrm{~Hz}$ (exceeding compensation by the pursuit system), all while the patient reads the visual acuity chart. Again, the smallest line read with less than three errors is recorded while the head is moving (eg, 20/50). A normal result is a drop of no more than two lines when the head is moving from the baseline static acuity. An abnormal result is a difference of two or more lines between static and dynamic acuity, likely with provocation of symptoms. Sensitivity and specificity of the DVA test varies greatly, as a result of varied methodology, such as passive (examiner moves head) versus active (subject moves head) oscillations, frequency of head movements $(1-7 \mathrm{~Hz})$, and position of head movement. Further, although it is recommended to perform DVA testing with the head tilted $20^{\circ}$ into flexion to isolate the horizontal canal, vision can be obscured for those wearing corrective glasses and the overall the range of visual acuity diminishes in upward gaze. Regardless, provocation of symptoms during the DVA test indicates injury-induced damage.

- Vestibular/ocular motor screen (VOMS): A modified version (or screen) of the DVA is incorporated in the VOMS by holding a 14-size type at arm's length and performing rapid head movements as described earlier. 
The VOMS includes five domains: 1) smooth pursuit, 2) saccades, 3) near point convergence, 4) VOR, and $5)$ visual motion sensitivity. The examiner measures for symptom provocation according to a graded subjective scale for each assessment, ranging from no symptoms (0) to severe (10) after each test and also includes three measurements of near point convergence. ${ }^{30}$ In a recent study of the VOMS, concussed athletes reported the highest percentage of symptom provocation (61\%) during administration of VOR testing. ${ }^{30}$ Because the VOMS relies primarily on symptom provocation, it should not be used in isolation.

- Advanced VOR testing: More sophisticated VOR testing is typically conducted in specialized dizziness and balance centers. Rotary chair testing assesses VOR function at slower speeds that are less associated with ADL but is sensitive to detect bilateral vestibular loss. High-velocity head rotation testing can better assess higher demands of VOR function associated with ADL and more dynamic activities. These active head rotation systems are often computerized, with recent incorporation of infrared video based on Halmagyi and Curthoys' work to more objectively measure the corrective saccades noted in the head thrust test. These systems can measure smaller corrective saccades (covert saccades) that are not otherwise observable, and indicate vestibular disruption; however, the evidence for VOR dysfunction after TBI is sparse. Advanced VOR testing holds the potential to identify subtle dysfunction in the vestibular system following TBI, especially if the individual reports vestibular symptoms.

\section{Treatment of VOR dysfunction}

Successful treatments depend on an accurate diagnosis to guide a management strategy. In regard to concussion, recommended components of the clinical assessment include a graded symptom checklist scale, review of past medical history to identify risk factors associated with a prolonged recovery, cognitive testing, cranial nerve assessment (with a focus on oculomotor control, including vergence), cervical range of motion, balance, gait, and vestibular testing. ${ }^{52-54}$

As an initial screening tool, VOMS can identify visual and/or vestibular dysfunction, although more diagnostic tests to confirm findings are advised before integrating visual and/or vestibular exercises in managing the rehabilitation process. Once the specific impairments localize the etiology, an appropriate care plan can be developed, which may include referrals, continued rest, and/or recommendations to begin a "return-to-activity" rehabilitation program.
With regard to sports-related concussion, the most recognized return-to-play program is the "Graded Exertional Step-Wise Approach" protocol endorsed by the National Athletic Trainers' Association. ${ }^{52}$ This protocol forms a foundation for the most widely recognized concussion guidelines described in the Zurich Consensus Concussion Statement ${ }^{55}$ and is a mandate in the majority of states' concussion legislation, as well as the college athletics and professional sports concussion management guidelines.

The stepwise approach provides a foundation and standardized guideline suitable for the majority of individuals with mild TBI, as $>80 \%$ of concussed adolescents resolve symptoms within 21 days of the injury with adequate rest and a gradual return to activities. ${ }^{3-6}$ For those individuals with residual visual-vestibular associated symptoms, the stepwise approach with exertion is not sufficient; rehabilitative interventions are needed.

The potential to rehabilitate VOR varies. VOR function frequently recovers spontaneously with time, which has been attributed to neuroplasticity, and does not require any intervention. For those individuals who do not recover with time, Herdman describes two primary approaches for vestibular intervention: 1) adaptation and 2) substitution or compensation due to significant vestibular loss of which both are accomplished through an exercise-based treatment program ${ }^{56,57}$ In cases of significant vestibular loss, the VOR, especially at higher velocities, does not return to its pre-morbid level of function ${ }^{58}$; however this is unlikely for concussion. When to begin vestibular therapy is debatable, although the VOR adaptation exercises themselves need to be context specific. ${ }^{44}$ Through repetitive exercises that induce retinal slippage, the central vestibular mechanisms (brainstem and cerebellum) will correct and thereby rehabilitate these error messages. Retinal slippage can be induced by rapid head movements while maintaining visual fixation on a target in the distance, known as gaze stability exercises. VOR exercises should follow testing parameters but be performed under a variety of distances (targets at arm's length to distances further away), under a variety of conditions (seated, standing, and walking) and in various planes (horizontal, vertical, and/or with head tilt). Of note, the cerebellum limits of learning are $<2.5 \mathrm{~Hz}$, whereas the VOR performs at much higher speeds. Thus, neuroplasticity outside the cerebellum may be involved in VOR rehabilitation..$^{59,60}$

Exercises should begin slowly while the individual is in a seated (static) position to assess whether symptoms of anxiety, dizziness, and nausea are exacerbated. VOR exercises should be gradually increased in velocity, but as speed increases, amplitude of the head movement should decrease. This conservative approach to gradually increase intensity is more 
effective than generating error messages that are too large for the capacity of the VOR system. ${ }^{56}$ This gradual exercise approach based on tolerance and recovery of exercise is also consistent with the graded stepwise approach for mTBI. ${ }^{52}$

In predicting recovery, risk factors for negative outcomes overlap, but not entirely, between vestibular rehabilitation and PCS. For instance, the sex of the individual does not appear to influence recovery from vestibular symptoms as it does for PCS symptoms, although a history of migraine, younger age, and mood disorder similarly predict outcome for vestibular impairment and PCS. ${ }^{61-64}$

\section{Current challenges in clinical management of TBI}

Vestibular function is vulnerable to TBI of any severity. The primary challenge for the diagnosis and management of VOR impairments following TBI is the limited knowledge arising from a small body of research. Sensory organization and balance testing post TBI have been studied predominantly, but static balance testing performed as a standard post-injury examination does not adequately represent the vestibular system dynamics. As a result, static balance testing shows a perceived lack of sensitivity to detect concussion-related impairments. Additionally, balance testing alone incompletely describes vestibular function, as VOR and VSR have unique neuronal pathways that can sustain damage independent of one another. Hence, VOR function more accurately represents vestibular system dynamics and is a priority for post-injury examination. ${ }^{30}$ With an absence of clear normative data for VOR function in specialized populations (eg, athletes and elderly), diagnosis and treatment of vestibular impairments become more complex, which can be mitigated partially by conducting baseline/pre-injury testing, where possible. Although VOMS is thought to have a high level of confidence in accurately identifying a concussion, it is primarily a symptom provocation test and should not be used in isolation to diagnose or implement exercises. Challenges with VOMS include inter-tester reliability, symptom provocation with testing after head trauma often having an anxiety component (especially with a prolonged recovery), and relying on symptom reporting, which can result in recall bias (especially if the person wants to be allowed to return to sports). Comprehensive vestibular therapy is indicated for a subset of individuals in the acute phase post injury showing uncompensated vestibular dysfunction ${ }^{65-67}$ but typically considered only with more chronic vestibular dysfunction (10-12 weeks). ${ }^{68}$ The shared circuitry between the visual and vestibular systems indicates that a comprehensive clinical examination is required to accurately identify central and peripheral involvement, including the ability to differentiate between a component of anxiety and/or cervicogenic involvement. The complexity of testing, interpretation, and rehabilitation programs necessitate trained providers, who may not be readily available in all clinics and even multidisciplinary centers. Concussion specialists are licensed health care professionals who have training in concussion management, adhere to best practices, and see a sufficient number of cases. ${ }^{54}$ These factors can not only limit access to care but also prescribe a financial burden that deters marketplace saturation.

\section{Future prospects}

The elevated public awareness and associated legislation regarding TBI will continue to grow and focus research efforts in the area of diagnosis and management. Standard clinical testing discussed here will be complemented by advances in imaging and biomarker diagnostic tools. Further refinements through iterative processes will continue to refine and develop specific tools for visual and vestibular dysfunction related to TBI, as evidenced by the VOMS as the newest screening tool. Concussion specialists must continue to collaborate and communicate with other clinicians, specialists, and researchers to build knowledge for the comprehensive diagnosis and management of concussion. Advancements and accessibility with mobile- and web-based technology could potentially fill this void and pave the way for best practices through data mining to recognize practice patterns and track individuals in real time. This platform provides opportunities for increased collaboration and communication to deliver evidence-based clinical care to improve quality of life. Regardless of TBI severity, successful outcomes depend on awareness, education, and a comprehensive interdisciplinary approach. The continuing inclusion of visual, vestibular, and cervicogenic symptoms in TBI assessment and management continues to develop best practices for TBI.

\section{Acknowledgment}

The authors thank Dr Barin and Dr Polec for providing technical assistance and reviewing the manuscript.

\section{Disclosure}

The authors report no conflicts of interest in this work.

\section{References}

1. Hoffer ME, Gottshall KR, Moore R, Balough BJ, Wester D. Characterizing and treating dizziness after mild head trauma. Otol Neurotol. 2004;25(2):135-138. 
2. Lau BC, Kontos AP, Collins MW, Mucha A, Lovell MR. Which onfield signs/symptoms predict protracted recovery from sport-related concussion among high school football players? Am J Sports Med. 2011;39(11):2311-2318.

3. Kontos AP, Elbin RJ, Schatz P, et al. A revised factor structure for the Post-Concussion Symptom Scale: baseline and postconcussion factors. Am J Sports Med. 2012;40(10):2375-2384.

4. McCrea M, Gusckiewicz KM, Marshall SW, et al. Acute effects and recovery time following concussion in collegiate football players: the NCAA Concussion Study. JAMA. 2003;290(10):2556-2563.

5. Guskiewicz KM. Assessment of postural stability following sportrelated concussion. Curr Sports Med Rep. 2003;2(1):24-30.

6. Covassin T, Elbin RJ, Harris W, Parker T, Kontos A. The role of age and sex in symptoms, neurocognitive performance, and postural stability in athletes after concussion. Am J Sports Med. 2012;35(3):185-196.

7. Cripps A, Livingston SC. The value of balance-assessment measurement in identifying and monitoring acute postural instability among concussed athletes. $J$ Sport Rehabil. 2013;22:67-71.

8. Naguib MB, Madian Y, Refaat M, Mohsen O, El Tabakh M, AboSetta A. Characterisation and objective monitoring of balance disorders following head trauma, using videonystagmography. J Laryngol Otol. 2012;126(1):26-33.

9. Chamelian L, Feinstein A. Outcome after mild to moderate traumatic brain injury: The role of dizziness. Arch Phys Med Rehabil. 2004;85:1662-1666.

10. Ernst A, Basta D, Seidl RO, Todt I, Scherer H, Clarke A. Management of posttraumatic vertigo. Otolaryngol Head Neck Surg. 2005;2(4):554-558.

11. Fitzgerald, DC. Head trauma: hearing loss and dizziness. J Trauma. 1996;132(4):554-558.

12. Kapoor N, Ciuffreda KJ. Vision disturbances following traumatic brain injury. Curr Treat Options Neurol. 2002;4:271-280.

13. Capó-Aponte JE, Urosevich TG, Temme LA, Tarbett AK, Sanghera NK. Visual dysfunctions and symptoms during the subacute stage of blast-induced mild traumatic brain injury. Mil Med. 2012;177(7):804

14. Suh M, Kolster R, Sarkar R, Ghajar J. Deficits in predictive smooth pursuit after mild traumatic brain injury. Neurosci Lett. 2006;401:108-113.

15. Jacobson GP, Shepard NT. Balance Function Assessment and Management. 2nd ed. California: Plural Publishing, Inc; 2016.

16. Dix MR, Hallpike CS. The pathology, symptomatology and diagnosis of certain common disorders of the vestibular system. Ann Otol Rhinol Laryngol. 1952;61:987-1016.

17. Dorigueto RS, Mazzetti KR, Gabilan YP, Gananca FF. Benign paroxysmal positional vertigo recurrence and persistence. Braz J Otorhinolaryngol. 2009;75(4):565-572.

18. Goldberg JM, Cullen KE. Vestibular control of the head: possible functions of the vestibulocollic reflex. Exp Brain Res. 2011;210(3-4): 331-345.

19. Pozzo T, Berthoz A, Papvov C. The effect of gravity on the coordination between posture and movement. In: Taguchi K, Igarashi M, Mori S, editors. Vestibular and Neural Front, Proceedings of the 12th International Symposium on Posture and Gait. Amsterdam: Elsevier; 1994:589-602.

20. Bronstein AM and Hood JD. The cervico-ocular reflex in normal subjects and patients with absent vestibular function. Brain Res. 1986;373(1-2): 399-408.

21. Pompeiano O. The tonic neck reflex: supraspinal control. In: Peterson BW, Richmond FJ, editors. Control of Head Movement. New York: Oxford University Press; 1988:108-119.

22. Peterson BW, Goldberg J, Bilotto G, Fuller JH. Cervicocollic reflex: its dynamic properties and interaction with vestibular reflexes. J Neurophysiol. 1985;54(1):90-109.

23. Della Santina CC, Potyagaylo V, Migliaccio AA, Minor LB, Carey JP. Orientation of human semicircular canals measured by threedimensional multiplanar CT reconstruction. J Assoc Res Otolaryngol. 2005;6(3):191-206.

24. Baloh RW, Sills AW, Honrubia V. Impulsive and sinusoidal rotatory testing. A comparison with results of caloric testing. Laryngoscope. 1979;89:646.
25. Jongkees LB. J. R. Ewald. Arch Otolaryngol. 1966;83(6):615-619.

26. Carleton SC, Carpenter MB. Afferent and efferent connections of the medial, inferior and lateral vestibular nuclei in the cat and monkey. Brain Res. 1983;278:29-51.

27. Brandt T, Dieterich M. Vestibular syndromes in the roll plane: topographic diagnosis from brainstem to cortex. Ann Neurol. 1994;36: 337-347.

28. Purves D, Augustine GJ, Fitzpatrick D, et al., editors. Central vestibular pathways: eye, head, and body reflexes. Neuroscience. 2nd ed. Sunderland, MA: Sinauer Associates; 2001.

29. Leigh RJ, Zee DS. The Neurology of Eye Movements. 4th ed. New York: Oxford University Press; 2006.

30. Mucha A, Collins MW, Elbin RJ, et al. A brief vestibular/ocular motor screening (VOMS) assessment to evaluate concussions: preliminary findings. Am J Sports Med. 2014;42(10):2479-2486.

31. Gottshall K, Drake A, Gray N, McDonald E, Hoffer ME. Objective vestibular tests as outcome measures in head injury patients. Laryngoscope. 2003;113:1746-1750.

32. Davies RA, Luxon LM. Dizziness following head injury: a neurotological study. J Neurol. 1995;242:222-230.

33. Thompson TL, Amedee R. Vertigo: a review of common peripheral and central vestibular disorders. Ochsner J. 2009;9(1):20-26.

34. Gizzi M, Riley E, Molinari S. The diagnostic value of imaging the patient with dizziness. Arch Neurol. 1996;53:1299-1304.

35. Scopaz KA, Hatzenbuehler JR. Risk modifiers for concussion and prolonged recovery. Sports Health. 2013;20(10):537-541.

36. Marar M, McIllvain NM, Fields SK, Comstock RD. Epidemiology of concussions among United States high school athletes in 20 sports. Am J Sports Med. 2012;40(4):747-755.

37. McCrea M, Guskiewicz K, Randolph C, et al. Incidence, clinical course, and predictors of prolonged recovery time following sport-related concussion in high school and college athletes. J Int Neuropsychol Soc. 2013;19(1):22-33.

38. Briscoe A and Mullur RS. Vertigo and Dizziness. In: Washington Manual $^{\circledR}$ of Outpatient Internal Medicine. Philadelphia: Lippincott Williams and Wilkins; 2012.

39. Peterson MC, Holbrook JH, Von Hales D, Smith NL, Staker LV. Contributions of the history, physical examination, and laboratory investigation in making medical diagnoses. West J Med. 1992;156:163-165.

40. Hampton JR, Harrison MJG, Mitchell JRA, Prichard JS, Seymour C. Relative contribution of history-taking, physical examination, and laboratory investigation to diagnosis and management of medical outpatients. Br Med J. 1975;2:486-489.

41. Ganz JC. Edwin Smith papyrus case 8: a reappraisal. J Neurosurg. 2014;120:1238-1239.

42. Heitger MH, Jones RD, Macleod AD, Snell DL, Frampton CM, Anderson TJ. Impaired eye movements in post-concussion syndrome indicate suboptimal brain function beyond the influence of depression, malingering or intellectual ability. Brain. 2009;132:2850-2870.

43. Anderson HA, Manny RE, Cotter SA, Mitchell GL, Irani JA. Effect of examiner experience and technique on the alternate cover test. Optom Vis Sci. 2010;87(3):168-175.

44. Zee DS. Vestibular adaptation. In: Herdman SJ, editor. Vestibular Rehabilitation. 2nd ed. Philadelphia, PA: FA Davis; 1999:77-87.

45. Tirelli G, Rigo S, Bullo F, Meneguzzi C, Gregori D, Gatto A. Saccades and smooth pursuit eye movements in central vertigo. Acta Otorhinolaryngol Ital. 2011;31(2):96-102.

46. Mosimann UP, Muri RM, Felblinger J, Radanov BP. Saccadic eye movement disturbances in whiplash patients with persistent complaints. Brain. 2000;123(4):828-835.

47. Cohen M, Groswasser Z, Barchadski R, Appel A. Convergence insufficiency in brain-injured patients. Brain Inj. 1989;3(2):187-191.

48. Halmagyi GM, Curthoys IS. A clinical sign of canal paresis. Arch Neurol. 1988;45:737-739.

49. Hain TC, Fetter M, Zee DS. Head-shaking nystagmus in patients with unilateral peripheral vestibular lesions. Am J Otolaryngol. $1987 ; 8: 36-47$ 
50. Jacobson GP, Newman CW, Safadi I. Sensitivity and specificity of the head-shaking test for detecting vestibular system abnormalities. Ann Otol Rhinol Laryngol. 1990;9:263-271.

51. Longridge NS and Mallinson AL. The dynamic illegible E-test. A technique for assessing the vestibular-ocular reflex. Acta Otolaryngol. 1987;103:(3-4):273-279.

52. Leddy JJ, Sandhu H, Sodhi V, Baker JG, Willer B. Rehabilitation of concussion and post-concussion syndrome. Sports Health. 2012; 4(2):147-154.

53. Broglio SP, Cantu RC, Gioia GA, et al; National Athletic Trainer's Association. National Athletic Trainers' Association: management of sport concussion. J Athl Train. 2014;49(2):245-265.

54. Parachutecanada.org [webpage on the Internet]. Solving the Concussion Crisis: Practical Solutions (Consensus 2015). Toronto. Available from: http://www.parachutecanada.org/research/item/solving-the-concussioncrisis-practical-solutions. Accessed November 15, 2015.

55. McCrory PM, Meeuwisse WH, Aubry M, et al. Consensus statement on concussion in sport: the 4th International Conference on Concussion in Sport held in Zurich, November 2012. Br J Sports Med. 2013;47: 250-258.

56. Herdman SJ. Advances in the treatment of vestibular disorders. Phys Ther. 1997;77:602-618.

57. Herdman SJ. Role of vestibular adaptation in vestibular rehabilitation. Otolaryngol Head Neck Surg. 1998;119:49-54.

58. Curthoys IS, Halmagyi GM. Vestibular compensation: a review of the oculomotor, neural, and clinical consequences of unilateral vestibular loss. J Vestib Res. 1995;5(2):67-107.
59. Dieringer N. Vestibular compensation: neural plasticity and its relations to functional recovery after labyrinthine lesions in frogs and other vertebrates. Prog Neurobiol. 1995;46(2-3):97-129.

60. Porrill J, Dean P. Cerebellar motor learning: when is cortical plasticity not enough? PLoS Comput Biol. 2007;3(10):e197.

61. Whitney SL, Rossi MM. Efficacy of vestibular rehabilitation. Otolaryngol Clin North Am. 2000;33(3):659-672.

62. Whitney SL, Wrisley DM, Marchetti GF, Furman JM. The effect of age on vestibular rehabilitation outcomes. Laryngoscope. 2002;112(10):1785-1790.

63. Wrisley DM, Whitney SL, Furman JM. Vestibular rehabilitation outcomes in patients with a history of migraine. Laryngoscope. 2002;23(4):483-487.

64. Topuz O, Topuz B, Ardiç FN, Sarhuş M, Ogmen G, Ardiç F. Efficacy of vestibular rehabilitation on chronic unilateral vestibular dysfunction. Clin Rehabil. 2004;18(1):7683.

65. Shepard NT, Telian SA. Programmatic vestibular rehabilitation. Otolaryngol Head Neck Surg. 1995;112(1):173.82.

66. Han BI, Song HS, Kim JS. Vestibular rehabilitation therapy: review of indications, mechanisms and key exercises. J Clin Neurol. 2011;7:184-196.

67. Ellis MJ, Leddy JJ, Willer B. Physiological, vestibuloocular and cervicogenic post-concussion disorders: An evidence-based classification system with directions for treatment. Brain Inj. 2015;29(2): 238-248.

68. Valvovich-McLeod TC, Hale TD. Vestibular and balance issues following sport-related concussion. Brain Inj. 2015;29(2):175-184.
Eye and Brain

\section{Publish your work in this journal}

Eye and Brain is an international, peer-reviewed, open access journal focusing on clinical and experimental research in the field of neuroophthalmology. All aspects of patient care are addressed within the journal as well as basic research. Papers covering original research, basic science, clinical and epidemiological studies, reviews and evaluations,

Submit your manuscript here: http://www.dovepress.com/eye-and-brain-journal

\section{Dovepress}

guidelines, expert opinion and commentary, case reports and extended reports are welcome. The manuscript management system is completely online and includes a very quick and fair peer-review system, which is all easy to use. Visit http://www.dovepress.com/testimonials.php to read real quotes from published authors. 